\title{
Responding to the 2018-2020 Ebola Virus Outbreak in the Democratic Republic of the Congo: Rethinking Humanitarian Approaches
}

\author{
Susannah H Mayhew (D) \\ Patrick Milabyo Kyamusugulwa ${ }^{2}$ \\ Kennedy Kihangi Bindu ${ }^{3}$ \\ Paul Richards ${ }^{4}$ \\ Cyrille Kiyungu ${ }^{5}$ \\ Dina Balabanova' \\ 'Department of Global Health and \\ Development, London School of Hygiene \& \\ Tropical Medicine, London, UK; ${ }^{2}$ Bukavu \\ Medical University College/Institut \\ Supérieur des Techniques Médicales de \\ Bukavu (ISTM-Bukavu), Bukavu, Eastern \\ Democratic Republic of Congo; ${ }^{3}$ Centre de \\ Recherche sur la Démocratie et le \\ Développement en Afrique (CREDDA), \\ Université Libre des Pays des Grands Lacs, \\ Goma, Democratic Republic of Congo; \\ ${ }^{4}$ School of Environmental Sciences, Njala \\ University, Freetown, Sierra Leone; \\ ${ }^{5}$ Hygiene, State Administration, Kikwit, \\ Democratic Republic of Congo
}

\begin{abstract}
The Democratic Republic of Congo (DRC) presents a challenging context in which to respond to public health crises. Its 2018-2020 Ebola outbreak was the second largest in history. Lessons were known from the previous West African outbreak. Chief among these was the recognition that local action and involvement are key to establishing effective epidemic-response. It remains unclear whether and how this was achieved in DRC's Ebola response. Additionally, there is a lack of scholarship on how to build resilience (the ability to adapt or transform under pressure) in crisis-response. In this article, we critically review literature to examine evidence on whether and how communities were involved, trust built, and resilience strengthened through adaptation or transformation of DRC's 2018-2020 Ebola response measures. Overall, we found limited evidence that the response adapted to engage and involve local actors and institutions or respond to locally expressed concerns. When adaptations occurred, they were shaped by national and international actors rather than enabling local actors to develop locally trusted initiatives. Communities were "engaged" to understand their perceptions but were not involved in decision-making or shaping responses. Few studies documented how trust was built or analyzed power dynamics between different groups in DRC. Yet, both these elements appear to be critical in building effective, resilient responses. These failures occurred because there was no willingness by the national government or international agencies to concede decision-making power to local people. Emergency humanitarian response is entrenched in highly medicalized, military style command and control approaches which have no space for decentralizing decision-making to "non-experts". To transform humanitarian responses, international responders can no longer be regarded as "experts" who own the knowledge and control the response. To successfully tackle future humanitarian crises requires a transformation of international humanitarian and emergency response systems such that they are led, or shaped, through inclusive, equitable collaboration with local actors.
\end{abstract}

Keywords: Democratic Republic of Congo, Ebola, pandemic response, humanitarian emergency, community, social science

\section{Background and Context}

The Democratic Republic of Congo (DRC) has experienced multiple humanitarian crises, including a brutal, exploitative colonial history, entrenched poverty and postcolonial neglect, eleven outbreaks of Ebola Virus Disease since 1976 and widespread, longstanding armed conflict and fragile state institutions. This means the reach of formal government structures, including healthcare provision, is frequently
Correspondence: Susannah H Mayhew Department of Global Health and Development, London School of Hygiene \& Tropical Medicine, 15-17 Tavistock Place, London, WCIE 9SH, UK

Email Susannah.mayhew@Ishtm.ac.uk 
disrupted or contested. The $11^{\text {th }}$ Ebola outbreak in DRC was declared on 1st June 2020 in Équateur Province, North Western DRC. It was declared over less than six months later (on 18th November 2020) having, in part, benefitted from the widespread availability of Ebola vaccines. ${ }^{1}$ A new $\left(12^{\text {th }}\right)$ outbreak, declared on February $7^{\text {th }} 2021$, may also benefit from vaccine availability.

A month after the $11^{\text {th }}$ outbreak was declared, the devastating tenth outbreak, the second largest Ebola outbreak in history, was finally declared over (on 25th June 2020). The tenth outbreak was first declared by the DRC government in Kinshasa in August 2018 in North Kivu and Ituri Provinces (later spreading to South Kivu) in Eastern DRC. ${ }^{1}$ It took almost two years to combat, claiming 2299 lives. $^{1}$ Widespread armed conflict hampered response efforts and was widely blamed for the failure of international and national responders to bring the outbreak under rapid control; however, many critical voices raised during the outbreak suggest a more complex explanation and a significant failure of the WHO-led response to learn clear lessons from the 2013-16 West African outbreak, the largest in history, particularly around the need for rapid involvement of frontline communities, localization of the response and trust building. ${ }^{2-6}$

Eastern DRC is, indisputably, a challenging context for any response effort. Dozens of militia groups have caused insecurity for the past 25 years killing around 15,000 people over the last decade and displacing millions in the last three years alone. ${ }^{7}$ Rebel groups belonging to the Allied Democratic Forces (ADF) are accused of many of the massacres. The ADF is thought to be a militia force of mainly Muslim Ugandans installed in the area since 1995 with the eventual aim of undertaking attacks against Kampala. On $30^{\text {th }}$ October 2019, in the midst of the Ebola epidemic, the Congolese Army launched an offensive against the $\mathrm{ADF}$, who subsequently retaliated, killing more than 200 civilians in Beni (North Kivu). Civilians in turn attacked the UN peace-keeping forces' bases there in frustration that the UN was unable to protect them. ${ }^{6}$ The Congolese army suffered further losses in January $2020 .{ }^{8}$ This is a kind of warfare in which it is not easy to see the opposed sides. ${ }^{9}$ The impotent UN presence was seen in many local peoples' eyes as connected to presence of the international Ebola-responders, who were therefore also regarded with hostility as all outsiders are treated with suspicion. This situation encourages local people to cope with crises by introversion in order to survive.

This follows a more general pattern of recent conflict in tropical Africa. A violence that appears arbitrary and unpredictable encourages strong local defensiveness and self- reliance. This was seen in wars in Liberia and Sierra Leone, where local civilian defense (similar to the heterogeneous local, armed defense groups in DRC sometimes termed "mai mai") protected communities but greatly increased the complexity of the eventual peace process. ${ }^{4,5}$ An unanticipated bonus, however, was that the resourcefulness and resilience of local defenders became an asset for Ebola response, as has been documented for the major West African outbreak of the disease in 2013-16. ${ }^{10}$ Studies showed that local activists sometimes explicitly labelling themselves as an Ebola defense force, modeled along earlier civil defense lines - mobilized a coherent response to the Ebola outbreak well before a national strategy or international support materialized; local learning was often rapid and inspired, such as improvising personal protective equipment and taking unilateral action to successfully quarantine isolated villages. ${ }^{2,10,11}$

Yet this local learning was initially ignored by international responders, as were community concerns, and little attempt was made to integrate them into a mutually acceptable and trusted coherent national response. ${ }^{2,11}$ Like in DRC, after the outbreak was declared, an international emergency response paradigm was put in motion based on hierarchical medical (and often militarized) responses that tended to ignore local knowledge and learning and conducted only token "community engagement", 212 This can undermine the effectiveness of crisis-responses, as well as failing to build longer-term resilience. Thus, in Sierra Leone emergency health interventions were made more difficult when people hid their sick, refusing to seek treatment and showing hostility to professional health workers. ${ }^{13-15}$ These same issues emerged in the North Kivu outbreak in DRC, where there appears to have been little learning from earlier but manifestly similar situations in West Africa. ${ }^{2}$ In Sierra Leone, the epidemic began to come under control when the concerns underlying these apparently perverse reactions were addressed, through (for example) local recruitment of burial teams and establishment of communitybased care centers. ${ }^{14,16}$

Local action and involvement are now widely acknowledged as key to establishing effective crisis-response, yet it remains unclear whether and how this was finally achieved in DRC. There is also little understanding of what community engagement really means in humanitarian contexts, what constitute "successful" approaches and why they work. ${ }^{17,18}$ In this review article, therefore, we apply a new analytical approach to critically review literature that describes on-theground challenges to the 2018-20 Ebola response in DRC, particularly in terms of involving communities and building trust. 


\section{Analytical Approach: An Institutional Resilience Lens for Crisis Response}

Through the 1990s and 2000s, much international attention was given to health systems strengthening. ${ }^{19-21}$ However, more recent interest in health systems resilience ${ }^{22}$ allows for consideration of health systems' capacity for agile responses, including to major crises, and how they are affected by these to adapt or transform. We examine the literature using an analytical framework developed by coauthors (SM, PR, and DB) for (and later informed by) research they conducted on the Ebola response in Sierra Leone (see: https://responding-to-ebola.org/). This is shown in Figure 1.

The framework draws on conceptualizations of resilience across a range of disciplines including health systems, management theory, resilience literature (in relation to systems, institutions, individuals), climate and environmental change (including notions of environmental resilience), and institutional theories from economics, sociology and anthropology. It allows us to systematically examine and understand complex humanitarian-response challenges.

Contemporary notions of resilience are heavily informed by ecological understanding (related to climate change and environmental resilience literature) which has more recently been applied in institutional management theory $^{23}$ Vulnerability and disruption of a system occurs when there is a critical "tipping point". In ecology a critical tipping point could be a catastrophic rise in $\mathrm{CO} 2$ levels; in a health system, it could be a catastrophic shock like a rapidly spreading Ebola epidemic, or an outbreak of armed conflict. This shock leads to vulnerability and collapse, or adaptation that may or may not lead to systemic transformation. This understanding provides the backdrop to our analysis which is concerned with examining how and why communities and health systems are disrupted, collapse, and in what situations they adapt or transform. To further inform our analysis, we draw on scholarship from the health policy and systems literature.

Central to our framework are both health systems institutions and social institutions - we examine whether and how they were disrupted by the Ebola crisis or able to respond in ways that enabled adaptation or ultimate transformation. Classic health policy scholarship, applied to understanding of health systems, emphasizes the need to understand the range and roles of actors (people) and their institutions (both formal and informal), key processes (including coordination, communication and governance) and wider political contexts. ${ }^{22,24,25}$ Health systems scholarship also distinguishes between hardware components (structures and inputs, including emergency funding and resources) and software which encompasses less tangible (but fundamental) elements like trust, power and relationships between people, that shape institutions, affect how systems function and how services are delivered. ${ }^{26,27}$ In

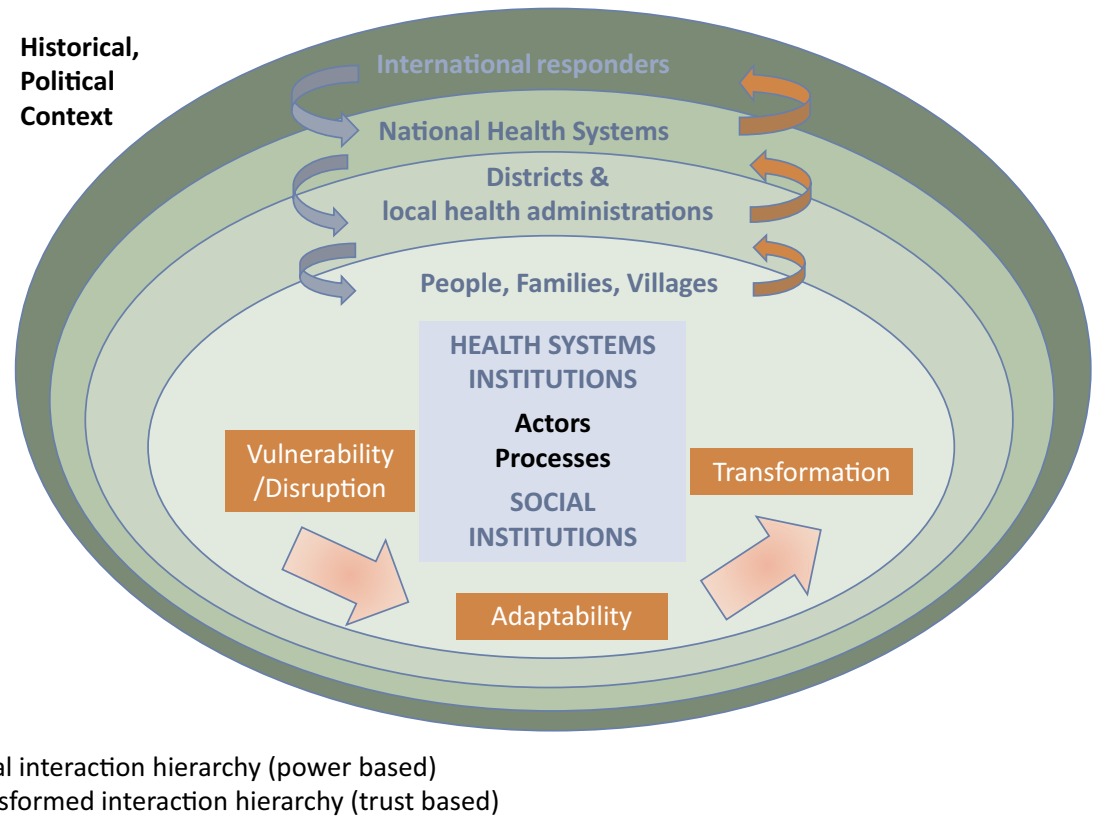

Figure I Conceptualizing health systems responses to outbreaks. 
our framework, these software concepts are manifest in the arrows that denote the interaction hierarchies that connect the different levels of action (from international to village).

The institutional level (both health systems institutions and social institutions) is central to understanding resilience (the ability to adapt or transform under pressure). Very often in crises, the problem is rigidity, and the inability of the systems to retain resilient core functions while having flexibility to adapt (or even transform) some of their elements and processes. This was seen very clearly in the case of Ebola burials in West Africa where communities maintained a high degree of social solidarity, in terrifying circumstances that might otherwise have led to social fracture and dispersal, through means such as large burial ceremonies that cemented social cohesion but at the same time were sources of Ebola infection. This poses the puzzle of how to secure institutional resilience flexible enough to meet the challenges of infection control.

Institutions are a major focus of attention across all social science disciplines, and theoretical frameworks vary. In economics, the approach of Douglass North has been influential. This emphasizes institutional change over time and focuses on the conditions under which "good" institutions are selected and thrive. ${ }^{28}$ The approach has been influential in debates on recent armed conflicts in Africa. ${ }^{29}$ Another approach - looking at how co-existing institutions combine or conflict - is sometimes credited to the influence of the economist Oliver Williamson, the sociologist Erving Goffman and the anthropologist Mary Douglas. Williamson points to the ways that institutions sometimes display conflicted organizational principles, and advocates transactions costs as a way of managing such disparities. ${ }^{30}$ Goffman and Douglas advocate a socalled neo-Durkheimian approach, in which attention is focused on the kinds of actions that cultivate or change institutional understandings and practices, including ritual action. $^{31,32}$ A key feature of this approach is to identify causes of institutional or organizational conflict and do things differently. We can return to the example of funerals under Ebola to illustrate this. Attempts to ban funerals as dangerous sources of infection were counter-productive in West Africa, since a funeral reinforces institutional values damaged by death - inter-family cooperation. ${ }^{13,16}$ A key to better infection control was not to ban funerals but to involve communities in generating a modified process of safe and dignified burial for those who died of the disease. ${ }^{33}$ Social and medical institutions needed to adapt their processes in order to continue to be effective.
Building on this, our understanding of the health system is not confined to one dimension. Most health policy and systems frameworks seek to identify a "locus of control" by actors in formal health systems institutions, usually with government playing a role as a "steward" overseeing the overall system functioning. ${ }^{20}$ Consequently, most frameworks that consider health system institutions and their governance focus primarily on formal health institutions and actors and national-level governance. ${ }^{34}$ Yet, as both the Ebola examples above and work on anti-corruption in the health system show, there may be a significant discrepancy between formal structures and informal practices, shaped by social norms and experiences which can undermine formal systems processes (and institutions) by redistributing power and access to resources. ${ }^{35}$ The lack of attention to local institutions and social networks and their interactions, particularly in terms of power, is a notable gap in both health systems and humanitarian response scholarship. We looked to scholarship outside the health sector to consider the relational aspects of how different actors, from different co-existing and interacting institutions, can work together with greater stakeholder inclusivity within and across different levels - an approach that has been termed "multi-modal" or "distributed governance". 36,37 Our framework therefore highlights the multiple levels at which health and social systems operate from the globalnational interface through the districts to the village and family level - and the relationships by which they interact. These relationships are functions of power and trust which are negotiated through interactions. ${ }^{38}$ In our framework, these are shown as top-down power-based relationships or bottom-up trust-based interactions. All of these elements are acknowledged to operate in a wider historical, political context.

In DRC multiple actors and institutions play important roles, including government and rebel leaders, local chiefs and headmen, traditional healers, village-based health workers, as well as village residents. The context is complex: ongoing, unpredictable armed conflict (from colonial to present times) has led to forced displacements, fragile state institutions, weak health systems (particularly in the areas worst affected by conflict), mistrust and poverty. In the midst of this are strong local cultures including a strong sense of local solidarity informed by Ubuntu thinking (ie, shared common humanity), traditional knowledge and traditional healing practices. In our analysis, we apply the conceptual 
framework described above, to identify key actors and institutions and analyze the socio-political context in which they operate and whether and how their relationships shaped the response to the 2018-20 Ebola response in DRC, to achieve system adaptation and transformation following the outbreak.

\section{Methods and Search Strategy}

Peer-reviewed journal literature were systematically searched from 1976 (when Ebola was discovered) until March 2020 across three databases: Embase, Global Health, Medline, yielding 112 articles after abstract screening. Search terms covered database-specific terms encompassing multiple variations of: Ebola AND Congo/ DRC AND humanitarian/epidemic response. For analysis of the 2018-20 response, we selected only publications relevant to that outbreak, but we retained papers relating to earlier Ebola responses in a separate file and drew on them where they held relevant insights for our background and discussion.

Additionally, after March 2020 Google Scholar searches for "Trust", "Ebola", "DRC" were conducted and four researchers working in DRC Ebola-response, or on trust in humanitarian responses in Africa, were emailed for suggestions for other relevant papers. Co-authors (PK, KB, CK) based in DRC also provided reports, papers and documents on the response. Some of these sources provided studies in French, including those written by Francophone African authors, although our database searches of peer-review publications were solely in English.

After screening of titles, abstracts and full texts from all sources, data from 41 retained documents were summarized in spreadsheet tables for analysis. Data were analyzed according to the domains in our analytical framework while allowing new themes to emerge. The narration of findings reflect the predominant themes in the literature around key actors, their relationship and role in system adaptation and transformation.

\section{Inclusion/Exclusion Criteria for Systematic Search of Databases}

Included documents: English language studies (or English translations of French texts); studies reporting primary data on response actions and/or consequences; progress reports detailing response actions; rapid surveys and research reports written to inform the response.
Excluded documents: non-English language (for which no English translation was available); clinical studies; conference proceedings; speculative modelling papers; morbidity/mortality reports; opinion pieces (unless they detailed frontline responses or data).

Given that DRC is francophone the limiting of articles to those written in English could have been seen as a serious limitation. However, it should be noted that many international frontline responders (from WHO, Médecins Sans Frontières (MSF) and other international agencies) published regularly in English throughout the outbreak. Furthermore, official polls, progress-reports and socialscience data collected by responders are available in English. Additional (unlimited) searches found few directly relevant articles in French. Our Congolese coauthors proposed documents in French. We feel, therefore, that it is unlikely that we have missed any obvious, significant sources that only appear in French.

\section{Challenges in Negotiating Relationships for Crisis Response During the 2018-2020 Ebola Outbreak in DRC}

The 2018 Ebola outbreak in North Kivu and Ituri Provinces was on a much larger scale than any previously experienced in DRC. WHO mobilized technical support far more rapidly than it had done in West Africa, with laboratory support and international agencies bringing personnel, equipment and resources. ${ }^{39}$ Furthermore, the 2018 epidemic was unique in having vaccines (developed during the West Africa outbreak) available for the first time and these constituted an important part of the response. ${ }^{40,41}$ A major adaptation the formal health system underwent was to mobilize to roll out the new Ebola vaccines as they arrived, despite the difficulties created by ongoing insecurity, vaccinating more than 320,000 people. ${ }^{6}$ Yet, despite a rapid technical international response and the availability of vaccines the outbreak became the second largest in history continuing for almost two years.

Relationships between health systems and social actors and institutions, shaped by their wider socio-political context, are key to understanding why this was so. The subsequent results sections of this paper focus on three key cross-cutting thematic issues that emerged from our review - violence and mistrust; local perceptions, communication 
and involvement; trust building - and how they enabled or obstructed system adaptation and transformation.

\section{Violence and Mistrust}

A number of papers point to two key factors compounding response efforts: the ongoing armed conflict, and community mistrust and lack of involvement. ${ }^{6,39,40,42}$ Two quantitative papers show clear associations of violence with an increase in estimated Ebola transmission rates $^{43}$ and a reduction in rapid case isolation and vaccine uptake. ${ }^{44}$ Violence in Eastern DRC has also endangered health personnel and, over years, destroyed facilities and compromised infrastructure. ${ }^{6}$ Similarly, two other studies show statistical correlations between mistrust and misinformation and a decreased likelihood of adopting preventive behavior including vaccine uptake, ${ }^{42,45}$ as well as outright hostility to responders. ${ }^{42}$

These two factors - violence and mistrust - and the institutions and actors that perpetrate them are deeply connected with each other. Years of armed conflict between rebel and government forces - at times meted out by both on civilians - has forged people's deep mistrust of state institutions and activities. ${ }^{42,46}$ The Kinshasa government had ignored outbreaks in poor, remote areas before ${ }^{47}$ but the opposition of many people in Eastern DRC to the Joseph Kabila government as well as the area's ongoing instability added another layer of disenfranchisement. Many authors note the failure of both the Kabila government and international forces to protect people from years of intimidation and massacres from armed rebel groups, as well as a long history of brutal colonial and postcolonial neglect and exploitation. ${ }^{6,10,48,49}$ Collectively these experiences entrenched mistrust of any authority and during the Ebola response this mistrust naturally extended to foreign "experts" and biomedical scientists who came in to stamp their authority on the response. ${ }^{4}$ Moreover, suspicions of the Kinshasa government were fueled further by the prevention of planned elections in 2018 which, though ostensibly because of the virus, was regarded as politically motived perpetuating suspicions that Ebola was a government-induced illness - a situation that was used by opposition political leaders to further undermine government legitimacy. ${ }^{50,51}$

Rohan and McKay $(2020)^{6}$ note how the response itself had exacerbated insecurity because international responders had sought securitization of their actions. In some places, road travel was so dangerous that (foreign) health responders travelled in armored vehicles wearing flak jackets and helmets; this then conflated medical responders with the armed forces that were so distrusted, which then legitimized attacks on Ebola response staff. ${ }^{6}$ These connections are corroborated by the local perspectives from North Kivu described in Box 1.

Moran (2018) ${ }^{48}$ cites a Ministry of Health official quoting information from his own team of anthropologists on the negative perceptions of government and international responders in the wider context of political and armed violence:

[t]he [Congolese] Government is criticized for not doing enough to make it safe. The UN is judged to be complicit in the massacres here, and for not protecting the

\section{Box I Perspectives from North Kivu}

Unpublished interview data collected from Beni, North Kivu, in December 2019 by a co-author (PMK), noted that there was considerable hostility at first, when the response was led by outsiders with expensive cars. People were suspicious of their motives, believing the outsiders wanted to kill them. This was because they saw the external responders as linked to recent massacres they had suffered, which had been ignored by the Congolese government and its army. A respondent described how since 2014, when killings started in the Beni area, up to the present day no international organization had intervened to assist family members who were victims of massacres (like orphans, host house members) but suddenly for Ebola more than 50 international agencies arrived in the area. Food aid was thought to be poisoned as part of the plot to kill them and was rejected; there were numerous locally backed attacks on health facilities. After these attacks on health centers, efforts were made to integrate local people into the response teams. Local armed Mai Mai groups (who sought to protect local communities from other militias) promoted work with local doctors, nurses, religious leaders and members of women's and youth associations. Nevertheless, many suspicions remained. When asked how Ebola survivors were regarded a respondent noted that when the survivors talked about the need to trust the medical responders they were dismissed as having been paid to say that.

The Mai Mai reportedly hold a variety of beliefs about Ebola, including that it was a plot by the ADF and other armed groups involved in previous massacres, to complete the destruction of the local Nande people. Local chiefs (who derive from locally recognized lineages but also have formal political legitimacy conferred by government) generally carry respect and authority, as do local churches, though they also reportedly contributed to local suspicions by denying the existence of the disease or misappropriating response-resources. This issue of misappropriation of emergency response funds and resources which came flooding in fueling widespread resentment, was a phenomenon in the West Africa outbreak too where it was known as "Ebola money". 60 
population except for a few battalions. And NGOs, people think they are here just to make money. (p.1296)

Local people saw "Ebola money" pouring in to a government that had failed to provide them with basic protection or infrastructure, and saw that money clearly benefitting elites, businesses and aid workers (who were visibly richer than locals) so they frequently questioned why there was money to fight Ebola but not the rebels causing such destruction. ${ }^{6,52}$ In data collected by international responders, compiled by the Social Science in Humanitarian Platform (SSHAP), one respondent notes that "refusal to wash hands is a political action because nobody is dealing with the massacres". 53 The widespread perception that the international community is not interested in the challenges local people face, beyond Ebola outcomes, was reinforced by events like the measles outbreak that killed more than 6600, mainly children, across DRC between January 2019 and June 2020 but received almost no international attention ${ }^{54,55}$ and the lack of attention to other diseases was noted in multiple "engagement" sessions run by responders. ${ }^{53,56-59}$

In this challenging context, in which all non-local institutions and actors are distrusted and local people frequently rely on their own resourcefulness to survive, working through community interlocutors and local frontline health workers to build trust is critical. The next sections examine the evidence on whether and how local people were involved and trust was built in the DRC Ebola response, and the extent to which lessons were learned from the West Africa outbreak.

\section{Local Perceptions, Communication and Involvement}

A "Grand Bargain" was signed in 2016 by over 60 major donors and humanitarian agencies, who pledged to recognize the critical role of local responders in humanitarian action. ${ }^{61}$ Despite a large literature on community participation in health systems research, ${ }^{17,62}$ this has not been applied to the context of crisis-response. Although a number of crisis-response scholars highlight that communities are not homogenous, ${ }^{38,63,64}$ there is little scholarship on understanding what constitutes "community" or "local" in crisis-response and the terms are frequently used uncritically. ${ }^{61}$ There was, in the 2018-20 outbreak, a concerted effort to engage with various members of communities to understand what their perceptions were. Rich qualitative data were collected from August 2018 at least until December 2019 by UNICEF, the International Federation of the Red Cross (IFRC), Oxfam and other international responders. This was compiled and analyzed, with recommendations for practice, by the Social Science in Humanitarian Action Platform in an excellent series of briefings. $^{65}$

The extent to which these recommendations were put into practice, however, is less than clear and aside from these "data collection" meetings held by responders, critics of the DRC response claim that in practice "community engagement often meant little more than issuing instructions" (p.1494). ${ }^{3}$ This is borne out by locally representative polls from mid-2019 (a year into the outbreak) which showed that engagement was still insufficient and more was "needed to demonstrate respect toward the community, involve local authorities and support meaningful participation and feedback" (\#18p.18). ${ }^{51}$

Although SSHAPS preparedness ${ }^{66}$ and behavioral briefings ${ }^{53,56-59}$ identify a wide range of potential stakeholders and trusted interlocuters, including traditional healers, we found no studies or reports confirming that these interlocutors had been engaged in any systematic way. The briefings also made a good attempt to systematically capture rumors and perspectives from people in Eastern DRC, some of which had clear, practical implications for simple changes, for example, the colors used for PPE were traditionally associated with death and bad omens, therefore, had a negative impact. ${ }^{56}$ The very first briefing, using data collected between August and October 2018, noted that "the more local the institution the more favorably it was seen by respondents" who wanted to see "their" people and doctors leading the local response. ${ }^{53}$ This intelligence, which reinforced what was already known from the West Africa outbreak on the need for local involvement and ownership, 2,16,67 appears not to have been acted on. By the final briefing, using data from November to December 2019 , there is a notable increase in negative perceptions in some areas, with respondents reporting widespread suspicions of the motives of responders and frustration with the response which was seen as deeply politicized. ${ }^{59}$ These suspicions and frustrations are corroborated by other, academic, studies. ${ }^{42,46}$

The potentially negative effect of rumors and myths on Ebola response is known from previous outbreaks, ${ }^{47,68}$ although we only found two academic papers analyzing these in the 2018-20 outbreak. Kasereka and Hawkes 
(2019) ${ }^{69}$ analyzed the rumors and myths that persisted in the early months of the outbreak, which "may have fueled the 'underground' transmission of Ebola, as patients sought care from traditional healers". As the epidemic progressed, they found that these rumors appeared to dissipate as biomedical transmission became generally accepted. People also rapidly took on board the zoonotic nature of the disease and the nosocomial aspects of its spread. Muzembo et al $(2020)^{50}$ found a range of beliefs about the causes and origins of Ebola and rumors fueled by widespread distrust in national political actors and international responders, regarded spreading Ebola as part of a multinational plot to kill local people.

Yet, despite a wealth of evidence about potentially dangerous rumors and practical recommendations for engaging and involving local authorities to build trust and help address them, there seems to have been little attempt to implement these leading to one frontline commentator accusing many efforts to engage with communities of being "tone deaf". 4 This is corroborated by a report, released in March 2019, from Translators Without Borders (TWB), who surveyed residents in Goma (North Kivu) about their understanding of key response messages. $^{70}$ A majority of written and oral communications were French or "standardized" Swahili (spoken in Uganda and Tanzania) which many respondents, particularly women and older people who were less literate, could not understand. Many key concepts relating to prevention and treatment were therefore misunderstood. TWB concluded that effective communication depends on key messages and material being designed in locally understood Swahili - which requires development and testing of materials as locally as possible. We found no evidence that these recommendations were acted on. Indeed, the final SSHAP briefing (data from December 2019) reported frustrations of frontline health workers who were left to translate key terms and acronyms themselves and found that local people's frustrations at lack of clarity in communications were taken out on the local workers, who consequently felt undermined. ${ }^{59}$ Such deficiencies contributed to undermining the positions and safety of local health workers who, despite being initially trusted by their communities, ${ }^{53,70}$ reported fearing attack from frustrated local communities as the epidemic progressed. ${ }^{58}$

Although important adaptions were made in terms of systematic collection of data on local perceptions that could have transformed response approaches to community engagement, communication and involvement, there seems limited evidence of any subsequent adaptation or transformation of practice. Poor communication and lack of meaningful community involvement (including local health workers) in shaping the response, risked further undermining trust.

\section{Trust-Building}

Trust is recognized by international agencies as a "building block" for fighting diseases in complex humanitarian emergencies. ${ }^{71}$ Despite this, we found a surprising dearth of literature or reports documenting any real actions or experiences of how trust was actually built with communities and local responders in the DRC outbreak. We therefore widened our search to include lessons from West Africa. Six papers were identified (five from West Africa) whose core findings on practical actions for trustbuilding and community engagement (which fosters trust) are shown in Table 1.

Of these studies, Gillespie et al $(2016)^{72}$ take a more traditional approach based on specific actions (particular activities and mechanisms) while the others detail approaches to, or principles of, engagement, that will build trust. Kasali (2019), ${ }^{46}$ the only study from DRC, emphasizes some of the issues described above on the need for clear, consistent communications to explain the strategies being implemented and emphasize their political neutrality, and the need for mechanisms to respond to ongoing community feedback. Two papers describe how national and international responders can build trust at local level. Enria et al (2016) ${ }^{63}$ highlight the importance of dialogue and engaging with intra-community power dynamics. Dada et al (2019) ${ }^{73}$ describe how they attempted to put in place a respectful two-way information flow during vaccine trials. In the fragmented context of DRC, such opportunities for dedicated community liaison and social science teams working with community are limited, nevertheless the principles of reciprocity and respectful relationships as well as relatable messaging are transferrable. Ryan et al (2020) ${ }^{74}$ "technologies of trust" emphasize open, reflexive and accountable relationships that genuinely listen to and incorporate local perspectives. Finally, Tsai et al's $(2020)^{75}$ interesting analysis identifies local "intermediary" response-volunteers who are embedded in their communities as particularly effective, in large part because they are known locally and are therefore vulnerable to local sanction, which gives them legitimacy. They then become trusted conveyors of information 


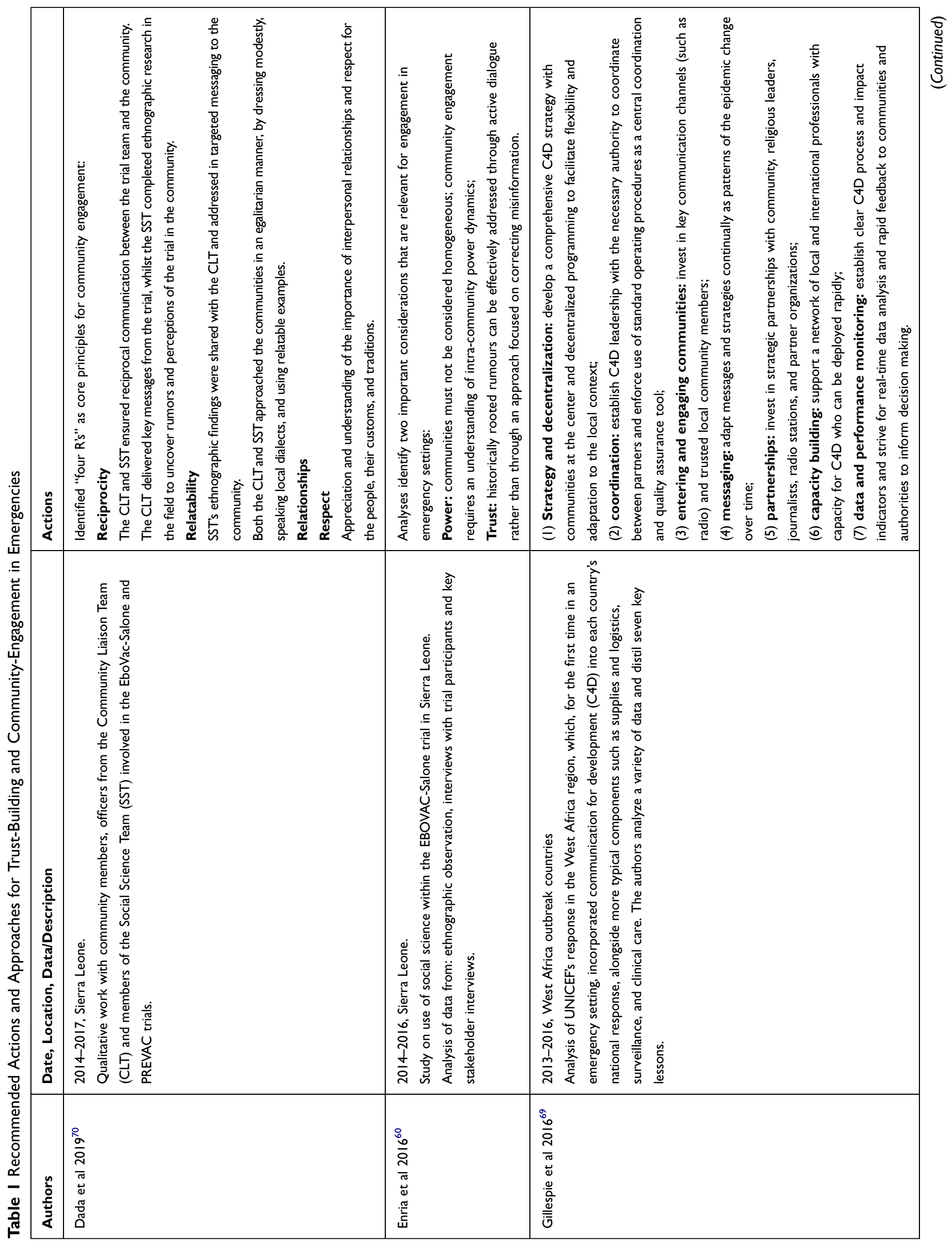




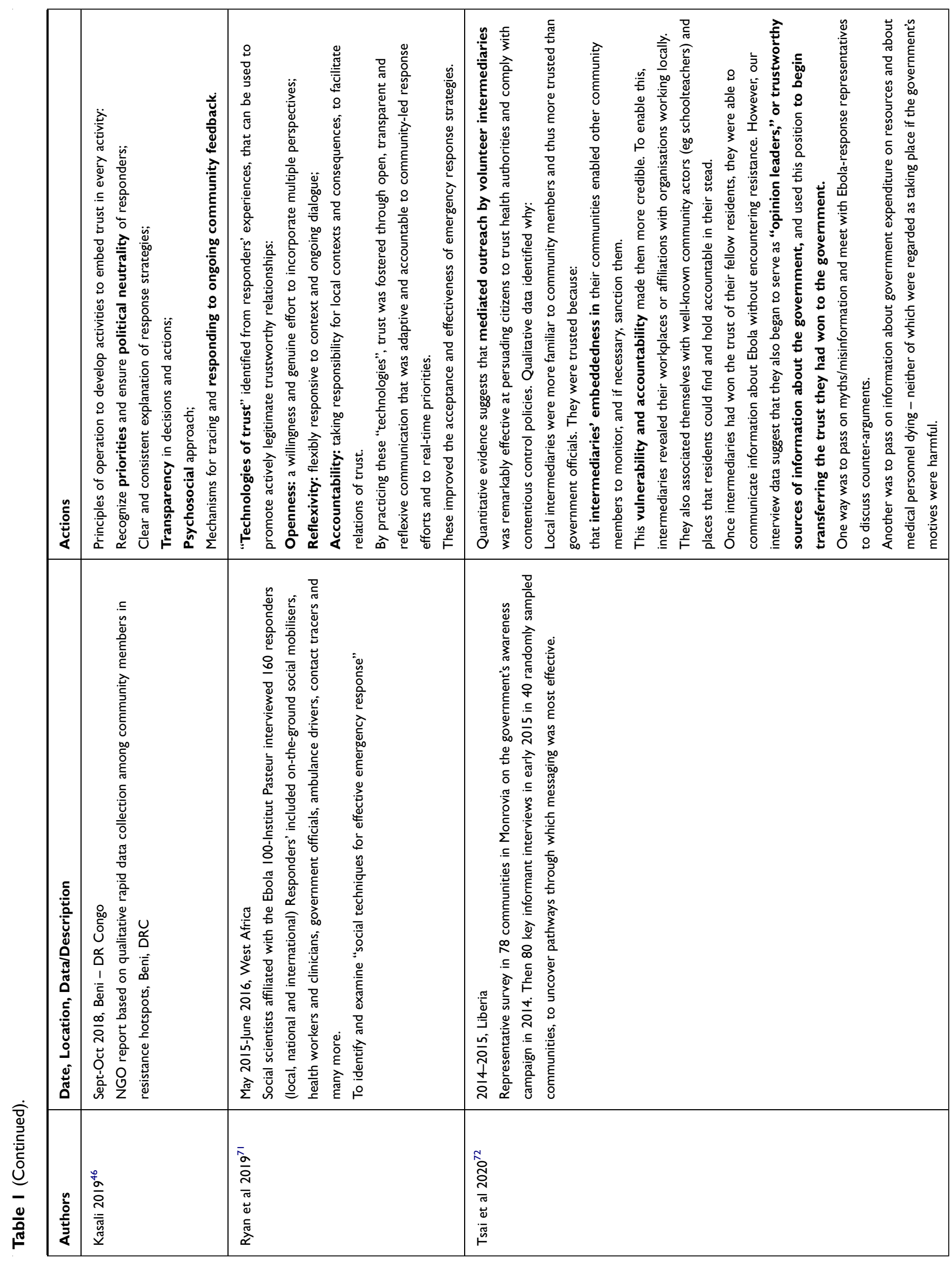


(interlocutors) both to and from "formal" (or outside) responders.

Gillespie et al (2016) ${ }^{72}$ (in relation to UNICEF's actions) call for engagement approaches to be formally incorporated (and funded) within the global humanitarian response architecture. While this is important, the evidence reviewed suggests that "engagement approaches" will not be effective unless they explicitly promote the principles or technologies of trust that have respectful, open and accountable relationships at their core, as the other papers highlight. Experience from West Africa shows that such respectful, accountable relationships were manifest when national and international responders were able to listen to community concerns and act on them by changing their responses - in other words, when the response systems had the flexibility to adapt or transform their procedures. Rohan and McKay $(2020)^{6}$ describe, and we have shown, the "evidentiary inertia" that was too often apparent in the DRC response. The safe and dignified burials program $^{33}$ was one of the few West Africa lessons that was acted on early in the DRC response. Many local communitybased burial teams were trained and supplied with personal protective equipment. However, other locally resented actions took much longer to change. Locally collected evidence in North Kivu showed deep unhappiness with the burning of household belongings outside the homes of infected people, but it took months to change IPC protocols for disposing of infectious items. Similarly, chlorine spray was widely used as a disinfection measure until a year into the response, despite clear evidence from West Africa that it was ineffective and created local resentment because of the negative health outcomes for people close to the spraying. ${ }^{6}$

Finally, an important insight on trust in the Ebola outbreak in North Kivu comes from an opinion piece contributed to the New England Journal of Medicine by VinhKim Nguyen (2019). ${ }^{4}$ The author is trained both as a medical doctor and as an anthropologist and was posted to an MSF Ebola case handling facility at Kayna, half-way between Goma and Butembo. Butembo was the epicentre of the outbreak in North Kivu, and the scene of armed attacks that partially destroyed MSF regional Ebola treatment hubs in February 2019. Using his anthropological training, and earlier experience in the West African Ebola epidemic, Nguyen took careful note of local suspicions. Why had the responders come only when people began to die of Ebola, and not during earlier outbreaks of other deadly diseases or massacres? This caused people to suspect there might be a hidden, ulterior motive for the huge international Ebola response. The implication was clear.
Change attitudes by changing the intervention (ie, transform). In response, the MSF team at Kayna took a more active approach to other diseases, by additionally treating severe cerebral malaria, typhoid, sepsis and even cholera. This helped diffuse the suspicion generated by a focus on one deadly disease among many. The same transition had been earlier achieved in Sierra Leone when large, closed and highly feared Ebola Treatment Centers (ETCs) were later complemented by local triage centers (Community Care Centers). In this case, rapid testing allowed Ebola cases to be spotted early enough for them to be safely transported to an ETC, while other patients were treated and discharged. ${ }^{16}$ This fostered a local sense of ownership of both the treatment facility and the diagnostic process. Resistance to the idea of transferring a patient to a more distant specialist Ebola handling facility lessened when patients with other diseases were being cured and discharged. The community saw itself as being better protected by a comprehensive interest in its welfare (a social institutional value), than by isolating out one dangerous disease among many. This in turn fostered the trust that proved so elusive in DRC.

The evidence shows that some adaptations were made by international responders to enable local involvement and build trust during the response, but these were limited or small scale and often very delayed. Indeed, as Box 2 illustrates, opportunities were not taken that could have enabled local intellectual leadership to advise on how to transform the response.

\section{Rethinking Humanitarian Response}

In our review we have sought to understand how institutions, processes and networks of actors interacted with each other to shape the response to the 2018-20 Ebola outbreak in DRC - and the implications of this for resilient outbreak response. To do so, we used our framework that focused on relationships between key actors and institutions and the extent to which this shaped the ability to adapt or transform the response. Local domains came through strongly in the literature as important in shaping the response - in particular the interaction between international responders and local actors. In the final sections of this paper we discuss the reasons why the international Ebola response in DRC showed only limited adaptation and little transformation; and the role of power dynamics and neo-colonialism in explaining this. 
Box 2 Local Perspectives on Local Intellectual and Scientific Involvement and Communication

Experiences of co-authors (PK, KKB, CK) in DRC show that there were serious communication deficiencies alongside a lack of space for local scientific or academic debate on Ebola outbreak responses. For example, Public Health and Medicine Faculties at universities including the Université Libre des Pays des Grands Lacs (ULPGL, in Goma, North Kivu) and Institut Supérieur des Techniques Médicales de Bukavu (ISTM-Bukavu, Eastern Congo), would have been appropriate institutions to engage to help to identify and shape critical solutions.

They were not involved, although some individual faculty members did provide input and help to collect data. Local frontline health workers were not consulted (despite being expected to implement many of the response actions) and frequently felt bypassed and undermined (e.g. when they were unable to explain the reasoning behind certain response actions that local people did not like or understand). There were no scientific presentations by humanitarian agencies or the national public health program that could have enabled locally appropriate debate about the response and more informed solutionbuilding.

Communications were frequently unclear and inadequate. Local radio programs presented preventive messages without any scientific

evidence; there was huge confusion about the vaccine as it was rolled out; and the quality of debate was poor. These deficiencies could all have been improved with the participation of local researchers, health workers and institutions.

\section{Limited Adaptation or Transformation in the DRC Response}

As we have seen there was deep mistrust in both national government and foreign UN agencies before the outbreak because of the failure of all parties to prevent armed violence against people in Eastern DRC. This mistrust then extended to international humanitarian responders and the violence and mistrust fueled each other. In this context, local people (including local health workers) were the only ones who could make trusted, locally acceptable and accountable decisions about response practices. In an emergency situation, when rapid containment of a deadly infectious disease is paramount, it is challenging in any country to involve key local stakeholders who do not have specialist medical knowledge. Nevertheless, while involving local stakeholders in the clinical response (eg, as surveillance officers, contact tracers, community mobilisers or burial team members) requires training and takes time, mistrust can be tackled from the beginning of a response if there is true commitment to local involvement and trust-building. In Liberia, the use of volunteer intermediaries by the government in its communication campaign was remarkably effective at persuading citizens to trust health authorities and comply with contentious control policies. ${ }^{75}$

Overall, we found limited evidence that national or international Ebola responders adapted to engage and involve local actors and institutions or respond to locally expressed concerns. Even when adaptations occurred, they were decided on and shaped by national or international actors rather than creating spaces for local actors (chiefs, frontline health workers, local researchers) to develop local initiatives to adapt or transform the response. There were positive attempts to systematically gather real-time data on people's perceptions of various aspects of the response (an adaptation learned from the West Africa outbreak-response), and both the international responders and the DRC Ministry of Health employed anthropologists to help with this. These data could have transformed approaches to community engagement, involvement and trust-building, but we found little evidence that this was so.

In terms of clinical practice, there was some evidence of adaptation in response to locally expressed concerns. Some changes were made to IPC practices and procedures to enable recruitment of local members of response teams. MSF made notable efforts to "normalize" its work at Kayna by adapting to treat other diseases after understanding that people were suspicious about MSF's motives in treating only Ebola patients, ${ }^{4}$ but this case was an exception. Learning from West Africa, safe and dignified burial procedures were conducted early on, but changes to other resented infection control procedures (burning of possessions, spraying with chlorine) were only slowly implemented, despite being identified early on. ${ }^{6}$ Part of the difficulty for enabling rapid clinical change is the time it takes to recruit and train local people to help deliver responsemeasures. Moreover, good exit-strategies from foreign aid are rare ${ }^{76}$ so there is seldom a coherent plan in which international responders build future capacity or help to repurpose the skills of those they have trained in emergency response. None of our reviewed papers discussed this but again, West African experiences hold lessons. In Sierra Leone local people, some of whom were earlier recruited and trained as Ebola surveillance officers and contact tracers now continue to be engaged by the Ministry of Health as Community Health Workers with (among others) an infectious disease surveillance function, thus helping to strengthen future emergency-response capacities. 
Across the response, a particular deficiency seems to have been the way in which community engagement was undertaken. Communities were "engaged" to understand their perceptions (ie, focus groups and meetings were held and data collated), but they were not engaged in the sense of taking part in decision-making or in the shaping subsequent responses. Indeed, the experiences of one coauthor (CK) show that local doctors were sometimes actively excluded. The lack of "respectful" or "meaningful" engagement was still being noted a year into the epidemic. $^{51}$ Respectful listening requires reshaping of practices to accommodate concerns, which in turn fosters trust and helps to change attitudes - this is known from Sierra Leone. ${ }^{10}$ Instead, SSHAPs data show that in DRC mistrust of international responders grew as the response went on. ${ }^{53,56-59}$ This points to a domain in which anthropological investigation is directly needed - into the way practices shape ideas. Consulting anthropologists for their opinion on the culture of Ebola-affected communities is very different from funding them to undertake close observational study of how the practices of Ebola responders are constituted, and how these practices sustain specific forms of institutional belief. ${ }^{32,77}$ Investment into local anthropology and social science capacities (so that a pool of local researchers, rather than foreigners, can be hired) would make a significant contribution to building longterm, resilient crisis-response systems.

Collectively, the evidence shows that while some adaptations to the response were made, they were limited or small scale and often delayed. Total transformation of the response, to a community-led, local responder-shaped response was not evident, despite the need for better trust-building and local involvement being widely recognized. Had local researchers, responders and intellectuals been properly consulted and their views acted on, various transformations could have been achieved (Box 3).

\section{Power Dynamics and Neo- Colonialism in Humanitarian Response}

It was significant that we found few documented cases of how trust was really built during the response, or any studies or documents that engaged in an analysis of power dynamics between different groups in DRC. In an insightful study from Sierra Leone, Enria $(2020)^{38}$ shows how "power is negotiated, reproduced, and contested through everyday practices and encounters" (p.2). Her
Box 3 Local Perspectives on Transforming Crisis-Response in DRC

Local intellectuals, including those co-authoring this paper (PK, KKB, $\mathrm{CK})$, are clear about the way in which the response interventions could and should have been adapted and transformed.

Lessons from previous outbreaks in DRC do not appear to have been well learned.

Local academic institutions should have been involved in discussions about how to shape the response and its communication in local languages. The connection between local suspicions of the Ebola response and previous massacres which neither UN peace keeping forces nor the Congolese Government have been able to prevent, needed to be recognized in messages as well as actions. To combat suspicion of the motives of government and international responders, other health needs should have been addressed alongside Ebola and local people (i.e. from Beni, from Butembo etc.) should have been more systematically integrated into local response teams. The knowledge of local frontline health workers should have been incorporated and acted on.

Strong partnerships should have been developed with a wide range of local authorities and "leaders of opinion" - through meetings/ dialogues as well as active mobilizing, training and hiring them for the response. These local stakeholders include local chiefs (i.e. locally recognized leaders at different levels of local government organization: chiefdom chiefs, groupement chiefs, locality chiefs), local churches (Christian and Muslim), health community workers (liaison health agents at health center), traditional healers (whose coordination office shares a compound with the Office of Health Inspection in North-Kivu), women's associations, youth associations, local civil society and administrative authorities (territory administration) and leaders of armed groups operating locally. Proper processes for local accountability needed to be put in place for transparency and to prevent misappropriation of protective items and supplies that were entrusted to them to distribute. Where armed conflict and breakdown of government authority continues,

treatment centers may need to be secured, but not without mobile teams using local languages to raise awareness about Ebola and help to build trust in the response.

study of Ebola response in a town on the border between Guinea and Sierra Leone during the West Africa outbreak reveals how local legitimacy and power were shaped through and by the international response. She cautions against using social science merely as a "cultural broker" to legitimize emergency responses and challenges responders to engage in a historically informed dynamic understanding of power and how it is contested and renegotiated during an emergency response and to consider the (often unpredictable) immediate and long-term consequences of this. None of the studies we identified on the DRC response engaged with these fluid power dynamics, shaped by their historical and political contexts, between local 
authorities, residents and international responders and their potential for both positive and negative impacts on local response. Yet local scholars have published on power dynamics and the need for participatory development and reconstruction in DRC. ${ }^{78}$ The most obvious reason that local power dynamics were ignored and trust failed to be built in DRC Ebola response is that there was no willingness on the part of either the national government or international agencies to consider the relationships between actors in a historical perspective or to concede decision-making power to local people.

Emergency humanitarian response is entrenched in highly medicalized, military style command and control approaches which have no space for engaging with decentralization of decision-making to "non experts". ${ }^{79,80}$ Emergency response approaches tend to hold a hierarchical view of scientific "knowledge", seen as invested mainly in "experts" from northern/western cultures, over local forms of knowledge. ${ }^{81}$ This has been called "monopolies of knowledge" by contemporary theorists on power, ${ }^{82}$ recognized in francophone discourse as "pensée unique d'origine coloniale" (colonial mindset) which is increasingly contested among the intellectual youth of DRC but seemingly ignored by humanitarian agencies. Monopolies extend to historical knowledge for which the contrasting narratives of the Ebola outbreak in Kikwit (a poor area some $500 \mathrm{~km}$ from Kinshasa) in 1995 are a case in point. The well-known and thriller-like US Centers for Disease Control (CDC) account of how their heroes saved the day is the received wisdom of the course of events. ${ }^{83}$ Local narrative, which is barely known, tells a very different story of how beleaguered local doctors recognized they had a rapidly spreading deadly outbreak, undiagnosed, on their hands. ${ }^{47}$ These doctors, including coauthor CK, meticulously documented its symptoms and progress and circulated these clinical descriptions among medical circles in Kinshasa alongside requests for help. They received nothing for many weeks until a foreign nun became infected and died - at which point embassies were alerted, the CDC became involved and the disease was finally diagnosed as Ebola and triggered long-awaited support. Similarly, there are memorials to the foreign nuns who died in Kikwit (as there are to the foreign nuns who perished in the first 1976 outbreak in Yambuku), but not to the 33-year-old Congolese nun, Sister Eugénie Kabila Musafiri, who died alongside them after nursing the sick at Kikwit General Hospital. She has been recognized by her own faith community,${ }^{84}$ but not by the medical or humanitarian response. ${ }^{47}$

Erasing or re-writing local histories in this way undermines the trust of future generations and becomes yet another manifestation of how global public health has been colonized in a way that devalues black lives and learning. DRC is no stranger to colonial exploitation and post-colonial neglect and in many ways here and in West Africa the international Ebola response has shown, as Richard Horton puts it in The Lancet, "how western countries bequeathed one more chapter of duplicity and treachery on the history of Africa." (p1494). ${ }^{3} \mathrm{He}$ and others cited in this review are clear that state-of-the-art interventions, like new vaccines, can never be substitutes for serious efforts, properly informed by history and social science, to respectfully build trust and cooperation with local populations as an essential framework for infection control and community public health. Alongside this, building resilient local emergency response systems requires sustained international commitment to long-term investment in strengthening decentralized local health systems, so that every public health crises can be effectively handled at the most local level.

To transform humanitarian responses, international responders can no longer be regarded as the "experts" who own the knowledge and control the response. The role of international agencies remains critical, but it should be focused on provision of finance, resources (including vaccines and mobile testing laboratories) and technical support - for the long term, not just for emergency-response. In the future, humanitarian response must move well beyond its control and command approach that is blind to local action, wisdom and power dynamics, to one that enables frontline responders (both local affected people and frontline health workers) to lead, shape and be locally accountable for, their own crisis-response.

COVID-19 could prove a game-changer. As countries worldwide question the (in)effectiveness of their responses, new social science discourse is emerging on the need to find new ways of decision-making and "evidence making" for emergency response to public health crises. There are calls for more social science led approaches that are "practice based", giving primacy to local voices to build flexible, listening responses. ${ }^{85-87}$ More broadly, there are calls to reclaim "comprehensive public health" that has participatory, equity-focused approaches at its core. ${ }^{88}$

People of the world are likely to continue to face outbreaks of new and re-emerging diseases of pandemic 
potential, like COVID-19. These outbreaks will often have to be tackled in complex and challenging settings, like that of DRC. In such settings, emergency responses to secure public health will only be successful (epidemiologically as well as socially) if they are able to learn the transferrable lessons from Africa. This requires a transformation of international humanitarian and emergency responses such that they are led, or shaped, through inclusive, equitable collaboration with local actors and that they invest in developing local capacities before they leave.

\section{Acknowledgments}

The authors thank Christian Mupika, a resident in Beni in 2019, who participated in awareness raising about Ebola and food distribution to people. He collected data locally on experiences of community response.

The development (by SM, PR and DB) of the analytical framework used in this article (Figure 1), was funded by the UK Medical Research Council, Grant number MR/ N015754/1.

\section{Disclosure}

The authors report no conflicts of interest for this work.

\section{References}

1. ECDC (European Centre for Disease Prevention and Control). 2020. Ebola outbreaks in the Democratic Republic of the Congo. Available from: https://www.ecdc.europa.eu/en/ebola-virus-disease-outbreakdemocratic-republic-congo-ongoing. Accessed March 27, 2021.

2. Ebola Gbalo Research Group. Ebola in DRC: when will the lessons from Sierra Leone be learned? The Lancet. 2019.

3. Horton R. Offline: the mistakes we made over Ebola. The Lancet. 395 (10208).

4. Nguyen VK. An epidemic of suspicion - Ebola and violence in the DRC. $N$ Engl J Med. 2019;380(14):1298-1299. doi:10.1056/ NEJMp1902682

5. Vogel C, Mathys G, Verweijen J, et al. Cliches Can Kill in Congo: the country's Ebola outbreak is spreading out of control-but it's not because of a fight over "conflict minerals.". Foreign Policy. 2019;30:2019.

6. Rohan H, McKay G. The Ebola outbreak in the Democratic Republic of the Congo: why there is no 'silver bullet'. Nat Immunol. 2020;21:591-594. doi:10.1038/s41590-020-0675-8

7. Uppsala Conflict Data Program. 2020. Available from: https://ucdp. uu.se/country/490. Accessed 8 December 2020.

8. JeuneAfrique. 2020. Available from: https://www.jeuneafrique.com/ 877627/politique/rdc-60-soldats-tues-dans-des-offensives-contre-desadf-a-beni/. Accessed 8 December 2020.

9. Richards P, Ed. No Peace, No War: An Anthropology of Armed Conflicts. Oxford: Currey; 2005.

10. Richards P. Ebola: How a People's Science Helped End an Epidemic. London: Zed Books; 2016.

11. Richards P, Mokuwa GA, Vandi A, Mayhew SH. Re-analysing Ebola spread in Sierra Leone: the importance of local social dynamics. PLoS One. 2020;15(11):e0234823. doi:10.1371/journal.pone.0234823
12. Chandler C, Fairhead J, Kelly A, et al. Ebola Response Anthropology Platform. Ebola: limitations of correcting misinformation. The Lancet. 2015;385(9975):1275-1277. doi:10.1016/S0140-6736(14)62382

13. Goguen A, Bolten C. Ebola through a glass, darkly: ways of knowing the state and each other. Anthropol Q. 2017;90(2):423-449. doi:10.1353/anq.2017.0025

14. Richards P, Mokuwa E, Welmers P, Maat H, Beisel U. Trust, and distrust, of Ebola Treatment Centers: a case-study from Sierra Leone. PLoS One. 2019;14(12):e0224511. doi:10.1371/journal.pone.0224511

15. Parker M, Hanson TM, Vandi A, et al. Ebola and public authority: saving loved ones in Sierra Leone. Med Anthropol. 2019;38(5):440454. doi:10.1080/01459740.2019.1609472

16. Mokuwa EY, Maat H, Mossel E. Rural populations exposed to Ebola Virus Disease respond positively to localised case handling: evidence from Sierra Leone. PLoS Negl Trop Dis. 2020;14(1):e0007666. doi:10.1371/journal.pntd.0007666

17. George AS, Mehra V, Scott K, Sriram V. Community participation in health systems research: a systematic review assessing the state of research, the nature of interventions involved and the features of engagement with communities. PLoS One. 2015;10(10):e0141091. doi:10.1371/journal.pone.0141091

18. O'Mara-Eves A, Brunton G, McDaid G, et al. Community engagement to reduce inequalities in health: a systematic review, meta-analysis and economic analysis. Public Health Res. 2013;1 (4).

19. World Bank. World Development Report 1993: Investing in Health. New York: Oxford University Press; 1993. Available from: https:// openknowledge.worldbank.org/handle/10986/5976License:CCBY3. OIGO. Accessed 8 December 2020.

20. WHO. Everybody's Business: Strengthening Health Systems to Improve Health Outcomes. WHO's Framework for Action. Geneva: World Health Organization; 2007.

21. Berman P, Bitran R. Health Systems Analysis for Better Health System Strengthening. Health, Nutrition, and Population (HNP) Discussion Paper. New York: World Bank; 2011. Available from: https://openknowledge.worldbank.org/handle/10986/13593License: CCBY3.0IGO. Accessed December 8, 2020.

22. Blanchet K, Nam SL, Ramalingam B, Pozo-Martin F. Governance and capacity to manage resilience of health systems: towards a new conceptual framework. Int $j$ Health Policy Manage. 2017;6(8):431435. doi:10.15171/ijhpm.2017.36

23. Dentoni D, Pinkse J, Lubberink R. Linking sustainable business models to socio-ecological resilience through cross-sector partnerships: a complex adaptive systems view. Business Soc. 2020. doi: $10.1177 / 0007650320935015$

24. Walt G, Gilson L. Reforming the health sector in developing countries: the central role of policy analysis. Health Policy Plan. 1994;9 (4):353-370. doi:10.1093/heapol/9.4.353

25. van Olmen J, Marchal B, Van Damme W, Kegels G, Hill PS. Health systems frameworks in their political context: framing divergent agendas. BMC Public Health. 2012;12:774. doi:10.1186/1471-2458-12-774

26. Sheikh K, Gilson L, Agyepong IA, et al. Building the field of health policy and systems research: framing the questions. PLoS Med. 2011;8(8):8. doi:10.1371/journal.pmed.1001073

27. Abimbola S, Negin J, Martiniuk AL, Jan S. Institutional analysis of health system governance. Health Policy Plan. 2017;32(9):13371344. doi:10.1093/heapol/czx083

28. North D. Institutions, Institutional Change and Economic Performance. Cambridge University Press; 1990; doi:10.1017/ CBO9780511808678

29. Acemoglu D, Robinson JA. Why Nations Fail: The Origins of Power, Prosperity and Poverty. London: Profile Books; 2012.

30. Williamson OE. The economics of organization: the transaction cost approach. Am J Sociol. 1981;87:548-577. doi:10.1086/227496

31. Goffman E. Interaction Ritual. New York: Doubleday; 1967.

32. Douglas M. How Institutions Think. London: Routledge; 1986. 
33. WHO. Protocol on safe and dignified burial [in Sierra Leone]. 2014. Available from: http://apps.who.int/bitstream/10665/137379/1/WHO_EVD_ GUIDANCE_burials_14.2_eng.pdf?ua=1. Accessed December 8, 2020.

34. Pyone T, Smith H, van den Broek N. Frameworks to assess health systems governance: a systematic review. Health Policy Plan. 2017;32(5):710-722. doi:10.1093/heapol/czx007

35. Camargo CB, Koechlin L. 2018. Informal governance: comparative perspectives on co-optation, control and camouflage in Rwanda, Tanzania and Uganda. In: Ammann C, Forster T, editors. African Cities and the Development Conundrum. Vol. 10. Geneva: The Graduate Institute;78-100. doi:10.1163/9789004387942 005

36. Arnold C. Fourth-generation environmental law: integrationist and multimodal. Environ Law Policy Rev. 2011;35(3):771-886.

37. Baldwin E, Rountree V, Jock J. Distributed resources and distributed governance: stakeholder participation in demand side management governance. Energy Res Soc Sci. 2018;39:37-45. doi:10.1016/j. erss.2017.10.013

38. Enria L. Unsettled authority and humanitarian practice: reflections on local legitimacy from Sierra Leone's borderlands. Oxford Devel Stud. 2020;48(4):387-399. doi:10.1080/13600818.2020.1828325

39. Shears P, Garavan C. The 2018/19 Ebola epidemic the Democratic Republic of the Congo (DRC): epidemiology, outbreak control, and conflict. Infect Prev Pract. 2020;2(1):no pagination. doi:10.1016/j. infpip.2020.100038

40. Kalenga OI, Moeti M, Sparrow A, et al. The ongoing Ebola epidemic in the Democratic Republic of Congo, 2018-2019. N Engl J Med. 2019;381(4):373-383. doi:10.1056/NEJMsr1904253

41. Jombart T, Jarvis CI, Mesfin S, et al. The cost of insecurity: from flare-up to control of a major Ebola virus disease hotspot during the outbreak in the Democratic Republic of the Congo, 2019. Euro Surveillance. 2020;25(2):no pagination.

42. Claude KM, Underschultz J, Hawkes MT. Social resistance drives persistent transmission of Ebola virus disease in Eastern Democratic Republic of Congo: a mixed-methods study. PLoS One. 2019;14(9): no pagination.

43. Wannier SR, Worden L, Hoff NA, et al. Estimating the impact of violent events on transmission in Ebola virus disease outbreak, Democratic Republic of the Congo, 2018-2019. Epidemics. 2019;28 (no pagination):100353. doi:10.1016/j.epidem.2019.100353

44. Wells CR, Pandey A, Mbah LDN, et al. The exacerbation of Ebola outbreaks by conflict in the Democratic Republic of the Congo. Proc Natl Acad Sci. 2019;116(48):24366-24372. doi:10.1073/pnas.1913 980116

45. Vinck P, Pham PN, Bindu KK, Bedford J, Nilles EJ. Institutional trust and misinformation in the response to the 2018-19 Ebola outbreak in North Kivu, DR Congo: a population-based survey. Lancet Infect Dis. 2019;19(5):529-536. doi:10.1016/S1473-3099(19)30063-5

46. Kasali N. Community Responses to the Ebola Response: Beni, North Kivu. Congo Initiative Bethesda Counseling Center; 2019. Available from: https://opendocs.ids.ac.uk/opendocs/handle/20.500.12413/ 14353. Accessed March 27, 2021.

47. Kiyungu C. 2015. Panic in Kikwit/Panique A Kikwit. Available from: https://responding-to-ebola.org/documents-en-francais/. Accessed December, 82020.

48. Moran B. Fighting Ebola in conflict in the DR Congo. The Lancet. 2018;392(10155):1295-1296. doi:10.1016/S0140-6736(18)32512-1

49. Kardas-Nelson M. Ebola in Sierra Leone and DRC: lessons learnt. $\mathrm{Br}$ Med J. 2019;366:15012. doi:10.1136/bmj.15012

50. Muzembo BA, Ntontolo NP, Ngatu NR, et al. Local perspectives on Ebola during its tenth outbreak in DR Congo: a nationwide qualitative study. PLoS One. 2020;15(10):e0241120. doi:10.1371/journal. pone. 0241120

51. Voices from Congo (2018-2019). Reports \#15-19 and Ebola Rapid Survey \#1. Harvard Humanitarian Initiative/UNDP. Available from: $\mathrm{http} / / /$ www.peacebuildingdata.org/research/drc. Accessed December $8,2020$.
52. Burki T. Ebola in the Democratic Republic of the Congo: 1 year on. Lancet Infect Dis. 2019;19(8):813-814. doi:10.1016/S1473-3099(19) 30360-3

53. Bedford J, Gercama I, Bardosh K. SSHAP Behavioural Data Compilation \#1, November 2018. 2018.

54. Potter C. 2019. Beyond Ebola: DRC Battles Measles and Cholera. Outbreak Observatory. Available from: https://www.outbreakobserva tory.org/outbreakthursday-1/7/18/2019/beyond-ebola-drc-battlesmeasles-and-cholera. Accessed March 27, 2021.

55. Dyer O. DRC faces new Ebola outbreak, covid-19, and measles all at once. $B M J$. 2020;396:m2219. doi:10.1136/bmj.m2219

56. Bardosh K. SSHAP Behavioural Data Compilation Report \#3, May 2019. 2019. Available from: https://www.socialscienceinaction.org/ resources/social-science-behavioural-data-compilation-no-3-ebolaoutbreak-eastern-drc-february-may-2019/. Accessed March 27, 2021.

57. Bardosh K, Gercama I, Bedford J. SSHAP Behavioural Data Compilation Report \#2, February 2019. 2019. Available from: https://www.socialscienceinaction.org/resources/social-science-beha vioural-data-compilation-drc-ebola-outbreak-november-2018-febru ary-2019/. Accessed March 27, 2021.

58. Bardosh K, Jones T, Bedford J. SSHAP Behavioural Data Compilation Report \#4, August 2019. 2019. Available from: https://www.socialscienceinaction.org/resources/social-science-beha vioural-data-compilation-no-4-ebola-outbreak-eastern-drc-juneaugust-2019/. Accessed March 27, 2021.

59. Bardosh K, Jones T, Tullock O. SSHAP Behavioural Data Compilation Report \#5, January 2020. 2020. Available from: https://www.socialscienceinaction.org/resources/social-science-beha vioural-data-compilation-5-ebola-outbreak-eastern-drc-septembernovember-2019/. Accessed March 27, 2021.

60. Shepler S. "We know who is eating the ebola money!": corruption, the State, and the Ebola Response. Anthropol Q. 2017;90(2):5173. doi:10.1353/anq.2017.0026

61. Roepstorff K. A call for critical reflection on the localisation agenda in humanitarian action. Third World Q. 2020;41(2):284-301. doi:10.1080/01436597.2019.1644160

62. George AS, Scott K, Mehra V, Sriram V. (2016) Synergies, strengths and challenges: findings on community capability from a systematic health systems research literature review. BMC Health Serv Res. 2016;16(Suppl 7):623. doi:10.1186/s12913-016-1860-1

63. Enria L, Lees S, Smout E, et al. Power, fairness and trust: understanding and engaging with vaccine trial participants and communities in the setting up the Ebovac-Salone vaccine trial In Sierra Leone. BMC Public Health. 2016;16(1):1140. doi:10.1186/s12889-016-3799-x

64. Wilkinson A, Parker M, Martineau F, Leach M. "Engaging communities": anthropological insights from the West African Ebola epidemic. Philosophical Transactions of the Royal Society of London. Series B, Biol Sci. 2017;372(1721):20160305. doi:10.1098/ rstb.2016.0305

65. SSHAP (2019-20). Available from: https://www.socialscienceinac tion.org/emergency/ebola-outbreak-drc-2019-20/. Accessed March 27, 2021.

66. Peyton D, Gercama I, Bedford J. Ebola preparedness and readiness in Goma. SSHAP Briefing. 2019;2019.

67. Mokuwa EY (2020), Epidemics and community values: the value of indigenous institutions in addressing development shocks in Sierra Leone. $\mathrm{PhD}$ thesis. Wageningen University

68. Kangoy AK, Muloye GM, Avevor PM, Li S. Review of past and present Ebola Hemorrhagic fever outbreaks in the Democratic Republic of Congo 1976-2014. Afr J Infect Dis. 2016;10(1):38-42. doi:10.4314/ajid.v10i1.8

69. Kasereka MC, Hawkes MT. 'The cat that kills people:' community beliefs about Ebola origins and implications for disease control in Eastern Democratic Republic of the Congo. Pathog Glob Health. 2019;113(4):149-157. doi:10.1080/20477724.2019.1650227 
70. TWB (Translators Without Borders). Missing the Mark? People in Eastern DRC Need Information On Ebola in a Language They Understand a Rapid Language Needs Assessment in Goma. DRC. 2019. 2019.

71. Gostin LO, Sircar NR, Friedman EA. Fighting novel diseases amidst humanitarian crises. Hastings Cent Rep. 2019;49(1):6-9. doi:10.1 $002 /$ hast. 970

72. Gillespie AM, Obregon R, El-Asawi R, et al. Social mobilization and community engagement central to the Ebola response in West Africa: lessons for future public health emergencies. Global Health. 2016;4 (4):626-646.

73. Dada S, McKay G, Mateus A, Lees S. Lessons learned from engaging communities for Ebola vaccine trials in Sierra Leone: reciprocity, relatability, relationships and respect (the four R's). BMC Public Health. 2019;19(1):1665. doi:10.1186/s12889-019-7978-4

74. Ryan MJ, Giles-Vernick T, Graham JE. Technologies of trust in epidemic response: openness, reflexivity and accountability during the 2014-2016 Ebola outbreak in West Africa. BMJ Global Health 2019;4(1):e001272. doi:10.1136/bmjgh-2018-001272

75. Tsai LL, Morse BS, Blair RA. Building Credibility and cooperation in low-trust settings: persuasion and source accountability in liberia during the 2014-2015 Ebola Crisis. Comp Polit Stud. 2020;53(1011):1582-1618. doi:10.1177/0010414019897698

76. Lee H. Exit strategy for aid programs: planning exit before entering. Int J Soc Sci Stud. 2017;5(7):30-35. doi:10.11114/ijsss.v5i6.2287

77. Suchman LA. Plan and Situated Actions: The Problem if Human Machine Communication. Cambridge University Press; 1987.

78. Kyamusugulwa P, Hilhorst D. Power holders and social dynamics of participatory development and reconstruction: cases from the Democratic Republic of Congo. World Dev. 2015;70:249-259. doi:10.1016/j.worlddev.2015.02.002
79. de Waal A. Militarizing global health. Boston Rev. 2014;1(3):229237. doi:10.14485/HBPR.1.3.7

80. Yamey G, Schäferhoff M, Hatchett R, Pate M, Zhao F, McDade KK. Ensuring global access to COVID-19 vaccines. The Lancet. 2020;395 (10234):1405-1406. doi:10.1016/S0140-6736(20)30763-7

81. Fairhead J, Leach M. Science, Society and Power: Environmental Knowledge and Policy in West Africa and the Caribbean. Cambridge University Press; 2003.

82. Gaventa J, Cornwall A. Power and knowledge. Reason P, Bradbury $\mathrm{H}$, editors. The Sage Handbook of Action Research: Participative Inquiry and Action. Vol. 2008, 2nd ed. Sage;2008:172-187.

83. Regis E. Virus Ground Zero: Stalking the Killer Viruses with the Centers for Disease Control. New York: Pocket Books; 1996.

84. Faithweb. 2020. Available from: http://newsaints.faithweb.com/ new_martyrs/martyrs_charity.htm. Accessed March 27, 2021.

85. Greenhalgh T. Will COVID-19 be evidence-based medicine's nemesis? PLoS Med. 2020;17(6):e1003266. doi:10.1371/journal. pmed.1003266

86. Rhodes T, Lancaster K, Lees S, Parker M. Modelling the pandemic: attuning models to their contexts. BMJ Global Health. 2020;5(6): e002914. doi:10.1136/bmjgh-2020-002914

87. Bardosh K, de Vries D, Stellmach D, et al. Towards People-Centered Epidemic Preparedness and Response: from Knowledge to Action. Soc Sci Res. 2019.

88. Loewenson R, Accoe K, Bajpai N, et al. Reclaiming comprehensive public health. BMJ Glob Health. 2020;5(9):e003886. doi:10.1136/ bmjgh-2020-003886
Risk Management and Healthcare Policy

\section{Publish your work in this journal}

Risk Management and Healthcare Policy is an international, peerreviewed, open access journal focusing on all aspects of public health, policy, and preventative measures to promote good health and improve morbidity and mortality in the population. The journa welcomes submitted papers covering original research, basic science, clinical \& epidemiological studies, reviews and evaluations,

\section{Dovepress}

guidelines, expert opinion and commentary, case reports and extended reports. The manuscript management system is completely online and includes a very quick and fair peer-review system, which is all easy to use. Visit http://www.dovepress.com/testimonials.php to read real quotes from published authors. 